Research Article

\title{
Pattern of adverse reactions of antipsychotics in a tertiary care hospital
}

\author{
Meenakshy T. Viswanathan ${ }^{1}$, Asha Sisupalan ${ }^{2}$, Vidhukumar Karunakaran ${ }^{3}$
}

${ }^{1}$ Department of Pharmacology, SUT Academy of Medical Sciences, Thiruvananthapuram, Kerala, India

${ }^{2}$ Department of Pharmacology, Government Medical College, Manjeri, Kerala, India ${ }^{3}$ Department of Psychiatry, Government Medical College, Thiruvananthapuram, Kerala, India

Received: 28 March 2016

Accepted: 27 April 2016

\section{*Correspondence to:}

Dr. Meenakshy T. Viswanathan, Email: drmeenakshysut @ gmail.com

Copyright: (c) the author(s), publisher and licensee Medip Academy. This is an openaccess article distributed under the terms of the Creative Commons Attribution NonCommercial License, which permits unrestricted noncommercial use, distribution, and reproduction in any medium, provided the original work is properly cited.

\begin{abstract}
Background: This study was undertaken to analyse the pattern of adverse drug reactions (ADR) of antipsychotics among patients attending the psychiatry outpatient department of a tertiary care centre.

Methods: Patients attending the psychiatry outpatient department who have been on treatment with one or more antipsychotics for more than 6 weeks were included in the study. Details about the prescription given in the previous appointment were collected. Various adverse effects associated with the use of antipsychotics were noted and analysed with special importance to obesity, elevated waist circumference and prolongation of QTc interval in ECG.

Results: The analysis of various adverse drug reactions in the study showed that the most common CNS side effects were drowsiness and tremor. The prevalence of severe EPS like parkinsonism, tardive dyskinesia and perioral tremors was very low. The prevalence of obesity and overweight was $47 \%$ and $14 \%$ respectively. The mean BMI of the study population was 24.44 . Among the commonly prescribed antipsychotics, prevalence of obesity and overweight was highest in those patients on clozapine. The prevalence of QTc prolongation is $22 \%$ in this study.

Conclusions: The increasing use of atypical antipsychotics is associated with a different pattern of adverse drug reactions when compared to the typical drugs. Even though the prevalence of EPS is low, there is increased prevalence of metabolic side effects like obesity and diabetes mellitus.
\end{abstract}

Keywords: Antipsychotics, ADR, Obesity, QTc prolongation

\section{INTRODUCTION}

Antipsychotic drugs are considered the cornerstone for the treatment of schizophrenia and other psychotic disorders. Earlier conventional antipsychotics were used. With the introduction of atypical antipsychotics use of conventional ones has come down.

In a study on drug prescription pattern in schizophrenia outpatients by Weinbrenner $\mathrm{S}$ et al atypical antipsychotics were prescribed in $64.6 \%$ subjects; the most common drugs being olanzapine (26.6\%), clozapine $(21.3 \%)$ and risperidone $(19 \%){ }^{1}$ Several publications have indicated that atypical antipsychotic drugs are superior in efficacy to conventional antipsychotic drugs especially with respect to control of negative symptoms and lack of extrapyramidal side effects, these being the limiting factors with the conventional drugs. ${ }^{2}$

A study on metabolic syndrome in outpatients receiving antipsychotic therapy by Mainara AS et al has shown that prevalence of metabolic syndrome was significantly 
higher in subjects on antipsychotics $(27.0 \%)$ and elevated body mass index was seen in $33.40 \%$ of them. ${ }^{3}$

A Taiwanese study on obesity in schizophrenic outpatients receiving antipsychotics showed the prevalence of obesity among male and female patients to be 2.74 and 2.51 fold respectively greater than the reference population. ${ }^{4}$ A study on weight gain after antipsychotic medication by Simpson MM et al has shown that treatment with atypical antipsychotics was associated with more weight gain than treatment with typical antipsychotics. The same study has commented that among the atypical drugs, olanzapine was associated with more weight gain than either clozapine or risperidone. ${ }^{5}$ Use of second generation antipsychotics has been associated with elevated blood sugar levels and triglyceridaemia. ${ }^{6}$

Considering the observations in the above mentioned studies, the consensus development conference on antipsychotic drugs and obesity and diabetes has recommended that monitoring of weight (BMI), waist circumference, blood pressure, fasting plasma glucose and fasting lipid profile at baseline and during follow up is to be done in patients receiving antipsychotics. ${ }^{7}$

Antipsychotics are also associated with cardiac adverse effects. Among atypical antipsychotics clozapine had been linked to serious cardiac problems. A study by Alexander $\mathrm{H}$ et al comparing the effect of ziprasidone, risperidone, olanzapine, quetiapine, thioridazine, and haloperidol on the QT interval showed that thioridazine produced the maximum prolongation. ${ }^{8}$

With these aspects in mind, this study was conducted with the objective to evaluate the frequency of adverse effects observed in patients on antipsychotics, with special relevance to adverse reactions like obesity, hyperglycemia and QTc interval prolongation in ECG.

\section{METHODS}

It was a prospective cross-sectional study conducted in the outpatient department of psychiatry in, government medical college, Thiruvananthapuram, a tertiary care hospital over a period of 6 months.

Ethical clearance was obtained from the institutional human ethics committee prior to the study. Confidentiality and anonymity of the patients' information were maintained during and after the study. Outpatients of either sex in the age group 18-65 years who have been on treatment with antipsychotics for more than 6 weeks were included in the study. Pregnant women and inpatients were excluded from the study. A written informed consent was obtained from the patient/guardian/relative.

All the relevant information regarding the patient were obtained and recorded in the preformed proforma. Details about the prescription given in the previous appointment were collected. Name, dose, route and frequency of antipsychotics and other co prescribed drugs given were recorded on the proforma. Blood pressure and pulse rate of the patients were recorded. Body weight in kilograms and height in centimetres was recorded. Waist circumference was measured in centimetres using a measuring tape. This measurement was taken at the end of a normal expiration, with the arms relaxed at the sides; at the midpoint between the lower margin of the last palpable rib and the top of the iliac crest (hip bone). ${ }^{9}$

The details about the various adverse drug reactions were recorded. The presence or absence of subjective side effects like drowsiness, giddiness, urinary retention, constipation, hypersalivation was obtained by questioning the patients and the accompanying person. Endocrine side effects like amenorrhea, irregular menstrual cycles and galactorrhea were also noted down after questioning them.

Presence of extrapyramidal symptoms like tremor, rigidity, akathisia, tardive dyskinesia and perioral tremor were recorded during the clinical examination. Patients were also examined to detect other adverse reactions like pedal edema. Any other adverse reaction was also noted down.

Fasting blood sugar levels and ECG findings of the patients were noted down. Results of total and differential WBC count of patients on clozapine were also recorded.

Body mass index of all the patients was calculated using the formula

$$
B M I=\frac{\text { Weight in kilogram }}{\text { Hight in meter } 2}
$$

The patients were grouped into categories of normal weight, overweight and obese based on consensus statement for diagnosis of obesity, abdominal obesity and the metabolic syndrome for Asian Indians and recommendations for physical activity, medical and surgical management. ${ }^{10}$

Normal BMI: $18.0-22.9 \mathrm{~kg} / \mathrm{m} 2$

Overweight: $23.0-24.9 \mathrm{~kg} / \mathrm{m} 2$

Obesity: > $25 \mathrm{~kg} / \mathrm{m} 2$

The cut off for abdominal obesity was taken as $80 \mathrm{~cm}$ for females and $90 \mathrm{~cm}$ for males based on the above mentioned consensus statement.

\section{Calculation of corrected QT interval (QTc)}

The QT interval is measured from the beginning of the QRS complex to the end of the $T$ wave in the lead with the longest interval and without a prominent $U$ wave. The 
most commonly used formula developed by Bazett, was used to calculate the corrected QT interval (QTc). The duration of RR interval immediately preceding the QT interval used for calculation is measured from the surface electrocardiogram and the QTc was calculated as given below. $^{11}$

\section{$\mathrm{QTc}=\mathrm{QT} / \sqrt{\mathrm{RR}}$ interval}

A value of more than $0.45 \mathrm{sec}$ was taken as prolonged corrected QT interval.

The data were sorted, coded and entered into statistical package for the social science for windows 18.0 (SPSS Inc., Chicago, IL) and subsequently analysed. Descriptive statistics was used for data analysis of the parameters. Chi-square statistics, $t$ test and ANOVA were also used for analysis.

\section{RESULTS}

Prospective evaluation of prescriptions of 185 patients on antipsychotics, attending the outpatient department of psychiatry during the 6 months was done. Data regarding the various associated adverse reactions was also analysed.

Majority of patients belonged to the age group of 26-35 years $(28.1 \%)$ Mean age of the patients was 36.59 years. Female predominance was observed. $52 \%$ of the patients were unemployed. Among those married (104), 24 were either separated or legally divorced.

BPAD was the commonest indication for prescription of antipsychotics $(40 \%)$, the next being schizophrenia $(33.5 \%)$ (Table 1).

Table 1: Distribution of cases based on diagnosis.

\begin{tabular}{|llc|}
\hline Diagnosis & Number of cases & Percentage \\
\hline $\begin{array}{l}\text { Bipolar affective } \\
\text { disorder(BPAD) }\end{array}$ & 74 & 40.0 \\
\hline Schizophrenia & 62 & 33.5 \\
\hline $\begin{array}{l}\text { Psychosis Not otherwise } \\
\text { specified (NOS) }\end{array}$ & 15 & 8.1 \\
\hline Delusional disorder & 10 & 5.4 \\
\hline Organic mood disorder & 4 & 2.2 \\
\hline $\begin{array}{l}\text { Schizo affective } \\
\text { disorder(SAD) }\end{array}$ & 4 & 2.2 \\
\hline Others & 16 & 8.6 \\
\hline Total & 185 & 100 \\
\hline
\end{tabular}

Most of the patients (65.4\%) had treatment duration of more than 2 years. Out of the 185 patients, 139 (75.1\%) were on monotherapy, 42 received 2 antipsychotics each and 4 received 3 antipsychotics each. Out of 185 patients
$83 \%$ were on atypical antipsychotics alone, $11 \%$ were on combination of atypical and typical antipsychotics and $6 \%$ were on typical antipsychotics alone (Figure 1).

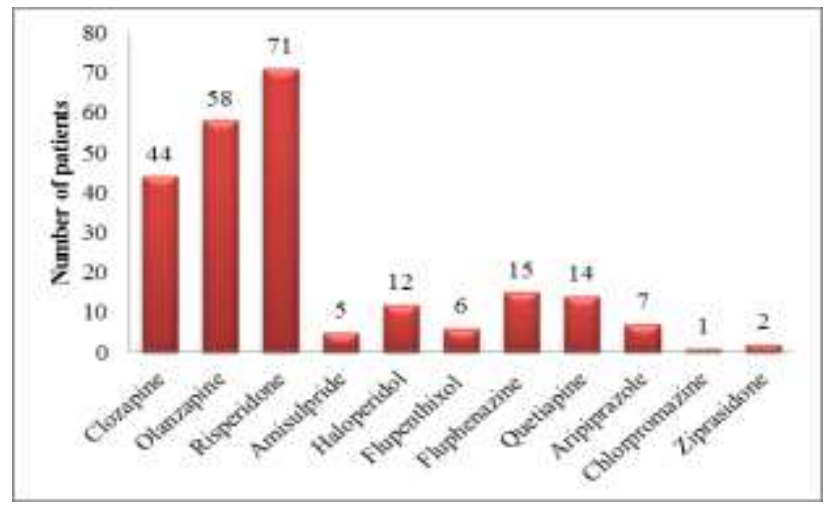

Figure 1: Use of various antipsychotics.

138 patients were prescribed other psychotropic drugs in addition to antipsychotics, the most common being mood stabilizers, followed by hypnotics, antidepressants and trihexiphenidyl. Out of 185 patients, 46 (25\%) were prescribed anticholinergic antiparkinsonian agent. Trihexiphenidyl was the only drug used for this purpose. It was commonly prescribed for patients on risperidone (34 patients) and those on typical antipsychotics.

The most common adverse drug reaction noted was drowsiness.

Tremor was the most common extra pyramidal side effect. Among patients on monotherapy with antipsychotics, tremor was seen to be maximum $(58.14 \%)$ in those on olanzapine. Tremor was seen in $30 \%$ of patients on quetiapine, $22.27 \%$ in clozapine group, $50 \%$ in those on haloperidol and $22.45 \%$ in those on risperidone.

Two patients presented with tardive dyskinesia and one patient with perioral tremors. 22 women had complaints of irregular menstrual cycles and risperidone was the most commonly prescribed antipsychotic in these women (7 patients). Four patients on olanzapine presented with bilateral pedal edema.

There were no cases with dystonia, akathisia, galactorrhea or gynecomastia.

Total and differential WBC count results were available in all patients on clozapine and no case of agranulocytosis was noted. Out of the 44 patients on clozapine, 19 complained of paradoxical hyper salivation (43\%).

Acanthosis nigricans and increased facial hair were observed in 5 women and all of them were obese. Clozapine was the most commonly prescribed antipsychotic in them (4 patients). 
There was a case of increased blood pressure following the patient's irregular intake of propranolol. Another patient reported with diarrhoea which could probably be due to increased dose of lithium. A patient who was not on olanzapine, presented with pedal edema probably due to the use of amlodipine (Figure 2).

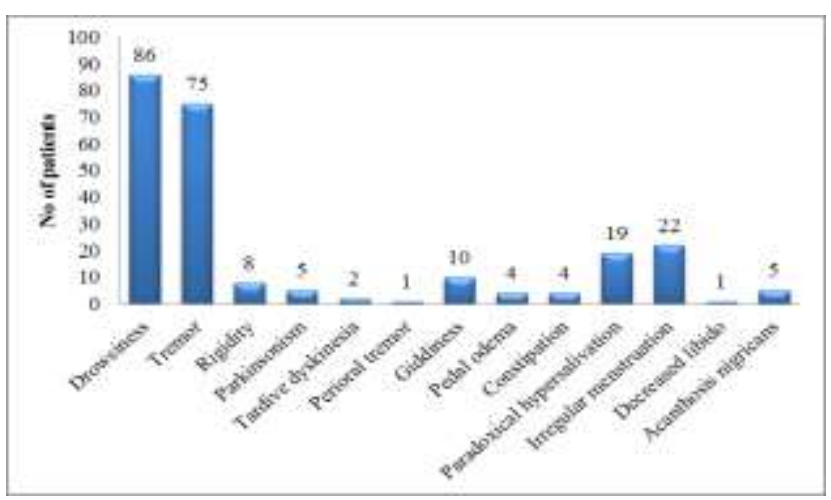

Figure 2: Prevalence of various adverse drug reactions.

Out of 86 patients who were obese 72 had their BMI in the range $25-29.9(38.92 \%)$ and $14(7.57 \%)$ had their $\mathrm{BMI}>30$. The mean BMI of the study population was 24.44 ( Figure 3).

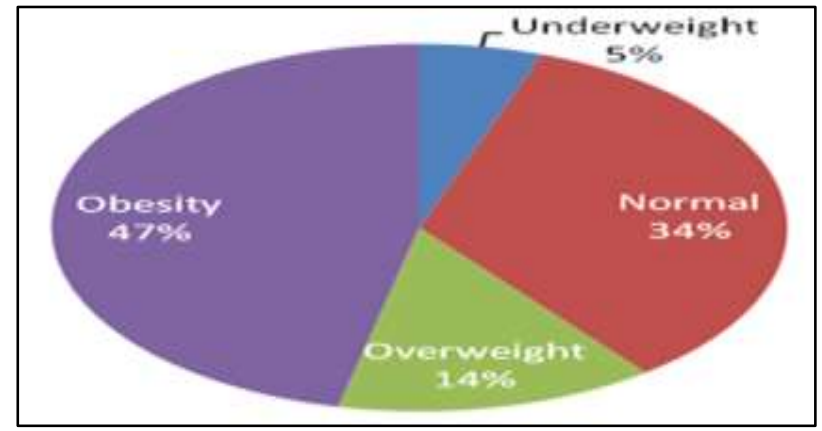

Figure 3: Distribution of cases based on body mass index.

Among the 3 most commonly prescribed antipsychotics (clozapine, olanzapine and risperidone) the prevalence of obesity was maximum with clozapine. The association of obesity and overweight with the use of various antipsychotics is not statistically significant (Table 2)

Out of 185 patients, 130 had elevated waist circumference (70\%). The mean waist circumference of the study population was $92.22 \mathrm{~cm} ; 93.97 \mathrm{~cm}$ for females and 89.52 $\mathrm{cm}$ for males.

Among the 3 most commonly prescribed antipsychotics (clozapine, olanzapine and risperidone) the prevalence of elevated waist circumference was maximum with clozapine. But the association of elevated waist circumference with the use of various antipsychotics was not statistically significant.

Table 2: Prevalence of obesity and overweight based on antipsychotics used.

\begin{tabular}{|lllllll|}
\hline & $\begin{array}{l}\text { No. of patients } \\
\text { receiving the drug }\end{array}$ & $\begin{array}{l}\text { No of patients } \\
\text { belonging to } \\
\text { obese/over } \\
\text { weight group }\end{array}$ & $\%$ & $\begin{array}{l}\text { No of patients } \\
\text { receiving the drug as } \\
\text { monotherapy }\end{array}$ & $\begin{array}{l}\text { No of patients } \\
\text { belonging to } \\
\text { obese/over } \\
\text { weight group }\end{array}$ \\
\hline Cloz & 44 & 31 & 70.45 & 22 & 16 & 72.73 \\
\hline Olan & 58 & 33 & 56.90 & 43 & 25 & 58.14 \\
\hline Risp & 71 & 41 & 57.75 & 49 & 28 & 57.14 \\
\hline Amis & 5 & 2 & 40 & 1 & 3 & 0 \\
\hline Halo & 12 & 10 & 83.33 & 4 & 0 & 75 \\
\hline Flup & 6 & 4 & 66.67 & 1 & 2 & 0 \\
\hline Fluph & 15 & 9 & 60 & 4 & 6 & 50 \\
\hline Quet & 14 & 9 & 64.29 & 10 & 2 & 60 \\
\hline Arip & 7 & 3 & 42.86 & 4 & 1 & 50 \\
\hline Zipr & 2 & 1 & 50 & 1 & 100 \\
\hline
\end{tabular}

Cloz- clozapine, olan- olanzapine, risp- risperidone, amis- amisulpride, halo-haloperidol, flup- flupenthixol, fluph- fluphenazine, quetquetiapine, arip- aripiprazole, zipr- ziprasidone

Among the 3 most commonly prescribed antipsychotics (clozapine, olanzapine and risperidone) the prevalence of diabetes mellitus and elevated blood glucose level was maximum with clozapine. But the association of diabetes mellitus and elevated blood glucose levels with the use of various antipsychotics was not statistically significant ( Figure 4). 


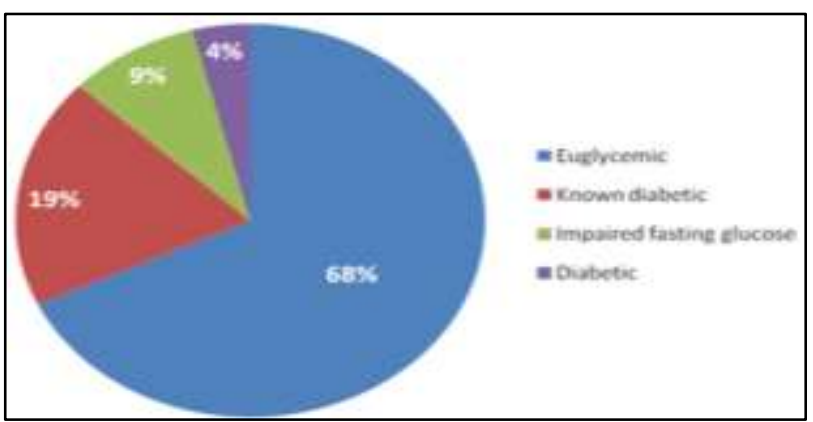

Figure 4: Prevalence of diabetes mellitus and abnormal glycemia.

Table 3: Prevalence of QTc prolongation.

\begin{tabular}{|lcc|}
\hline QTe Interval & No. of Patients & Percentage \\
\hline QTc Interval- normal & 55 & 77.5 \\
\hline QTc Interval >0.45 seconds & 16 & 22.5 \\
\hline Total & 71 & 100 \\
\hline
\end{tabular}

Among the patients receiving single antipsychotic, prevalence of QTc prolongation was maximum in patients on quetiapine, 3 out of the 5 patients on quetiapine had prolonged QTc interval ( Table 3).

\section{DISCUSSION}

Antipsychotics play a crucial role in the management of psychosis, mood disorders and other psychiatric conditions. Very often they have to be taken on long term basis. This study was undertaken to determine the pattern of adverse drug reactions among patients visiting the psychiatry outpatient department who were on antipsychotics.

The present study thus showed an increased use of atypical drugs which may be attributed to their increased efficacy and better tolerability profile compared to the typical antipsychotics. International guidelines recommend using second generation antipsychotics as first-line treatment for persons with psychosis. ${ }^{2,12,13}$

A total of 11 different antipsychotics were prescribed in this study, out of which four were typical antipsychotics which include haloperidol, chlorpromazine, flupenthixol and fluphenazine. The atypical antipsychotics prescribed include clozapine, olanzapine, risperidone, quetiapine, aripiprazole, ziprasidone and amisulpride.

Among the atypical antipsychotics risperidone was the most commonly prescribed drug. This is consistent with the finding in the study by Silvia Alessi-Severini et all and Bret MC et al. ${ }^{14,15}$

The use of antipsychotics is associated with many adverse reactions, the most important being the extrapyramidal symptoms. Though the increased use of atypical antipsychotics has reduced the incidence of EPS, a different set of metabolic side effects are associated with their use now. The analysis of various adverse drug reactions in the study group showed that the most common CNS side effect was drowsiness. Among the extrapyramidal symptoms, tremor was the commonest adverse effect.

Among patients on monotherapy with antipsychotics tremor was maximum $(58.14 \%)$ in those receiving olanzapine. Tremor was seen in $30 \%$ of patients on quetiapine, $27.27 \%$ of those on clozapine, $50 \%$ of those on haloperidol and $22.45 \%$ of those on risperidone. According to Tarsy D et al the atypical antipsychotics can be tentatively ranked by EPS risk (excluding akathisia and neuroleptic malignant syndrome) in the following order: clozapine<quetiapine<olanzapine $=$ ziprasidone, and at higher doses, risperidone is ranked with a higher EPS risk than olanzapine and ziprasidone. ${ }^{16}$

Studies have shown that most of the typical drugs and risperidone have a high incidence of EPS when compared with the other atypical drugs. ${ }^{17}$ But in this study, tremor was seen to be less in patients on risperidone and typical drugs when compared to other atypical drugs, which could be due to the fact that majority of the patients on risperidone and typical antipsychotics were receiving central anticholinergic drugs as co-prescription. Another factor could have been the clinicians not preferring risperidone or typical agents in patients who developed tremor.

Rigidity and parkinsonism were seen in less than $5 \%$ of the study population. Tardive dyskinesia was seen in two cases. These patients with TD had been on treatment for 4 years and 20 years respectively. Perioral tremors were seen in one patient with treatment duration of 13 years. The low prevalence of severe EPS like parkinsonism, tardive dyskinesia and perioral tremors in the study population could be due to the increased prescription of atypical antipsychotics and co prescription of antiparkinsonian anticholinergic drugs.

Though ten patients had complaints of giddiness, there was no postural fall in blood pressure. Out of the 44 patients on clozapine 19 complained of sialorrhea, accounting for a prevalence of $43 \%$, while in a similar study by Davydov L et al it was $54 \% .{ }^{18}$ The difference could be due to the difference in the prescribed dose of clozapine.

4 patients on olanzapine presented with bilateral pedal oedema. Similar case reports of olanzapine induced pedal oedema have been published before. ${ }^{19}$

In this study, though none of the female patients complained of amenorrhea, 22 women had complaints of irregular menstrual cycles $(19.64 \%$ of the total no of women). Risperidone was the most commonly prescribed antipsychotic in these women (7 patients). The EIRE study by Bobes $\mathbf{J}$ et al has found higher rates of both 
sexual dysfunction and reproductive side effects with risperidone compared with olanzapine, quetiapine, and haloperidol. ${ }^{20}$ This is consistent with the finding in our study.

As many studies have pointed out the increased prevalence of obesity and metabolic syndrome in patients on antipsychotics, the prevalence of obesity, elevated waist circumference and diabetes mellitus was determined in our study population.

In this study the prevalence of obesity and overweight was $47 \%$ and $14 \%$ respectively. Prevalence of obesity in the population of Kerala is $24.3 \%$ in males and $34 \%$ in females (according to WHO guidelines) as per the third national family health survey. ${ }^{21}$ The prevalence of obesity in the study population was much higher than this. The mean BMI of the study population is 24.44 which is much higher than the mean BMI of the general population of India. $^{22}$ (20.2 for men and 20.5 for women in the age group 15-49).

Among the commonly prescribed antipsychotics, prevalence of obesity and overweight was highest in those on clozapine $(70 \%)$. This finding is consistent with the following studies. In the study by Theisen FM et al prevalence rates of obesity were $64 \%$ in patients treated with clozapine, $56 \%$ for other atypical antipsychotics $30 \%$ for typical antipsychotics. ${ }^{23}$ Taylor and McAskill concluded that all atypical antipsychotics, with the exception of ziprasidone have been associated with weight increase, clozapine showing the maximum prevalence. ${ }^{24}$ In the study by Allison et al, weight gain was maximum with clozapine. ${ }^{25}$

Prevalence of elevated waist circumference was $70 \%$ in the study population. As abdominal obesity is an important factor contributing to metabolic syndrome, elevated waist circumference increases the risk for co morbidities in the study population. Among the commonly prescribed antipsychotics (clozapine, olanzapine, ripseridone), prevalence of elevated waist circumference was maximum in patients on clozapine. Similarly the prevalence of metabolic syndrome was seen to be maximum with clozapine in a study by J. Steven Lamberti et al (53.8\%). ${ }^{26}$

As per this study, $23 \%$ of the patients were diabetic and $9 \%$ had impaired fasting glucose. This is higher than the prevalence reported in Thiruvananthapuram in Kerala $(16.3 \%){ }^{22}$ Among the 3 most commonly prescribed antipsychotics (clozapine, olanzapine and risperidone), the prevalence of diabetes mellitus and abnormal blood glucose level was maximum with clozapine in the present study. In a study by Lund BC et al in patients aged 20 to 34 years who were on clozapine, the incidence of both diabetes and hyperlipidaemia was increased. ${ }^{27}$ In the study by Henderson and colleagues, subjects treated with clozapine and olanzapine showed significant insulin resistance compared to those treated with risperidone. ${ }^{28}$
The finding in the present study is consistent with these studies.

In the present study, prevalence of obesity, elevated waist circumference and abnormal glycaemia among patients receiving fluphenazine and haloperidol was high. While similar studies show that the prevalence of the above mentioned adverse effects was low in patients on fluphenazine and haloperidol. ${ }^{27,1,29}$ This difference could be due to the clinician's preferential use of these drugs in patients subsequent to the development of obesity and/or diabetes mellitus following the use of atypical agents.

The prevalence of QTc prolongation was $22 \%$ in this study. One patient had a QTc of $500 \mathrm{msec}$. Of the 16 patients with prolonged QTc, 9 were on antipsychotics alone. The rest were also receiving other psychotropic drugs like antidepressants, mood stabilizers, and hypnotics. Among the patients receiving single antipsychotic (47 patients), prevalence of QTc prolongation was found to be maximum in patients on quetiapine (3 out of 5 patients ). ${ }^{4}$ Out of 14 patients on olanzapine monotherapy also had prolonged QTc. A review article by $\mathrm{R}$ Welch et al have shown that antipsychotics can be ranked based on the mean prolongation of QTc intervals as risepridone>quetiapine>olanzapine. ${ }^{30}$ The disparity seen in the present study could be due to the fact that other factors which affects the QTc interval has not been taken into account. Prevalence of QTc prolongation is a significant finding in the study. But this needs further evaluation to determine if antipsychotics alone or other co-prescribed drugs are responsible for this particular side effect.

The limitations of this study were: As this was a cross sectional study many patients didn't report with their FBS results and ECG. Hence the prevalence of hyperglycemia and QTc prolongation could be assessed only in a fraction of the study population. Fasting lipid profiles of the patients could not be assessed, which if done would have given a better picture of the prevalence of metabolic syndrome.

\section{CONCLUSION}

The increasing use of atypical antipsychotics is associated with a different pattern of adverse drug reactions when compared to the typical drugs. Even though the prevalence of EPS is low, there is increased prevalence of metabolic side effects like obesity and diabetes mellitus. There was also increased prevalence of QTc prolongation.

\section{ACKNOWLEDGEMENTS}

The authors extend sincere gratitude to the Head of department and other colleagues in the department of psychiatry for their help and valuable suggestions. They are extremely grateful to the patients who agreed to be 
part of this study, without whose co-operation this study would have been impossible.

Funding: No funding sources

Conflict of interest: None declared

Ethical approval: The study was approved by the Institutional Ethics Committee

\section{REFERENCES}

1. Weinbrenner S, Assion H, Stargardt T, Busse R, Juckel G, Gericke CA. Drug prescription patterns in schizophrenia outpatients: analysis of data from a german health insurance fund. Pharmacopsychiatry. 2009;42(02):66-71.

2. Barnett D. Guidance on the use of newer (atypical) antipsychotic drugs for the treatment of schizophrenia 43, national institute for clinical excellence, London, Technology Appraisal Guidance; 2002.

3. Sicras-Mainar A, Blanca-Tamayo M, Rejas-Gutiérrez J, Navarro-Artieda R. Metabolic syndrome in outpatients receiving antipsychotic therapy in routine clinical practice: a cross-sectional assessment of a primary health care database. Eur Psychiatry. 2008;23(2):100-8.

4. Hsiao C, Ree S, Chiang Y, Yeh S, Chen C. Obesity in schizophrenic outpatients receiving antipsychotics in Taiwan. Psychiatry Clin Neurosci. 2004;58(4):403-9.

5. Simpson MM, Goetz RR, Devlin MJ, Goetz SA, Walsh BT. Weight gain and antipsychotic medication: differences between antipsychotic-free and treatment periods. J Clin Psychiatry. 2001;62(9):694-700.

6. Tarricone I, Casoria M, Gozzi BF, Grieco D, Menchetti M, Serretti A, et al. Metabolic risk factor profile associated with use of second generation antipsychotics: a cross sectional study in a community mental health centre. BMC Psychiatry. 2006;6:11.

7. Consensus Development conference on antipsychotic drugs and obesity and diabetes. Diabetes Care. 2004;27(2):596-601.

8. Glassman AH, Bigger JT. Antipsychotic drugs: prolonged QTc interval, torsade de pointes, and sudden death. Am J Psychiatry. 2001;158(11):1774-82.

9. Part 3: training and practical guides section 3: guide to physical measurements (step 2) WHO STEPS Surveillance; 2011.

10. Misra A, Chowbey P, Makkar BM, Vikram NK, Wasir JS, Chadha D, et al. Consensus statement for diagnosis of obesity, abdominal obesity and the metabolic syndrome for Asian Indians and recommendations for physical activity, medical and surgical management. J Assoc Physicians India. 2009;57:163-70.
11. Mirvis DM, Goldberger AL: Electrocardiography; in Libby (editors), braunwald's heart disease: a textbook of cardiovascular medicine, $8^{\text {th }}$ ed. Saunders. 159-60.

12. Lehman AF, Lieberman JA, Dixon LB, McGlashan TH, Miller AL, Perkins DO, et al. Practice guideline for the treatment of patients with schizophrenia, second edition. Am J Psychiatry. 2004;161(2):1-56.

13. The expert consensus guideline series. Optimizing pharmacologic treatment of psychotic disorders. J Clin Psychiatry. 2003;64(12):2-97.

14. Alessi-Severini S, Biscontri RG, Collins DM, Kozyrskyj A, Sareen J, Enns MW. Utilization and costs of antipsychotic agents: a Canadian populationbased study, 1996-2006. Psychiatr Serv 2008;59(5):547-53.

15. Bret M, Bret P, Pariente A, Fourier-Réglat A. The use of atypical antipsychotics in French psychiatric hospitals. Pharmacy World and Science. 20071;29(5):551-6.

16. Tarsy D, Baldessarini RJ, Tarazi FI. Effects of newer antipsychotics on extrapyramidal function. CNS Drugs. 2002;16(1):23-45.

17. Bobes J, Rejas J, Garcia-Garcia M, RicoVillademoros F, Garcia-Portilla MP, Madrigal M, et al. Frequency of extrapyramidal adverse reactions in schizophrenic outpatients treated with risperidone, olanzapine, quetiapine or haloperidol: the results of the EIRE study. Clin Drug Invest. 2002;22(9):609-22.

18. Davydov L, Botts S. Clozapine-induced hypersalivation. Ann Pharmacother. 2000;34(5):662-5.

19. Nayak V, Chogtu B, Devaramane V, Bhandary PV. Pedal edema with olanzepine. Indian J Pharmacol. 2009;41(1):49-50.

20. Bobes J, Portilla GA, Rejas MP, Ndez GM, RicoVillademoros, et al Frequency of sexual dysfunction and other reproductive side-effects in patients with schizophrenia treated with risperidone, olanzapine, quetiapine, or haloperidol: The results of the EIRE study. Journal of Sex and Marital Therapy. 2003;29:125-47.

21. Third national family health survey. Mumbai: international institute for population sciences; 2006.

22. Raman Kutty V, Joseph A, Soman CR. High prevalence of type 2 diabetes in an urban settlement in Kerala, India. Ethn Health. 1999;4(4):231-9.

23. Newcomer JW, Haupt DW, Fucetola R, Melson AK, Schweiger JA, Cooper BP, et al. Abnormalities in glucose regulation during antipsychotic treatment of schizophrenia. Arch Gen Psychiatry. 2002;59(4):337-45.

24. Taylor DM, McAskill R. Atypical antipsychotics and weight gain a systematic review. Acta Psychiatr Scand. 2000;101(6):416-32.

25. Allison DB, Mentore JL, Heo M, Chandler LP, Cappelleri JC, Infante MC, et al. Antipsychoticinduced weight gain: a comprehensive research synthesis. Am J Psychiatry. 1999;156(11):1686-96. 
26. Lamberti JS, Olson D, Crilly JF, Olivares T, Williams $\mathrm{GC}, \mathrm{Tu} \mathrm{X}$, et al. Prevalence of the metabolic syndrome among patients receiving clozapine. Am J Psychiatry. 2006;163(7):1273-6.

27. Lund BC, Perry PJ, Brooks JM, Arndt S. Clozapine use in patients with schizophrenia and the risk of diabetes, hyperlipidemia, and hypertension: a claimsbased approach. Arch Gen Psychiatry. 2001;58(12):1172-6.

28. Henderson DC, Cagliero E, Copeland PM, Borba CP, Evins E, Hayden D, et al. Glucose metabolism in patients with schizophrenia treated with atypical antipsychotic agents: a frequently sampled intravenous glucose tolerance test and minimal model analysis. Arch Gen Psychiatry. 2005;62(1):19-28.

29. Theisen FM, Linden A, Geller F, Schäfer H, Martin M, Remschmidt $\mathrm{H}$, et al. Prevalence of obesity in adolescent and young adult patients with and without schizophrenia and in relationship to antipsychotic medication. J Psychiatr Res. 2001;35(6):339-45.

30. R Welch, P Chue. Antipsychotic agents and QT changes. J Psychiatry Neurosci. 2000;25(2):154-60.

Cite this article as: Viswanathan MT, Sisupalan A, Karunakaran V. Pattern of adverse reactions of antipsychotics in a tertiary care hospital. Int $\mathrm{J}$ Basic Clin Pharmacol 2016;5:991-8. 